\title{
ANALISIS STRATEGI PENINGKATAN PENERIMAAN PAJAK BUMI DAN BANGUNAN PERDESAAN DAN PERKOTAAN SERTA EFEKTIVITAS PENERIMAANNYA DI KABUPATEN KEPULAUAN SIAU TAGULANDANG BIARO
}

\author{
Eflin R. Mamuko ${ }^{1}$, Jullie J. Sondakh ${ }^{2}$, Victorina Z. Tirayoh ${ }^{3}$ \\ 1,2,3 Jurusan Akuntansi, Fakultas Ekonomi dan Bisnis, Universitas Sam Ratulangi, Jln. Kampus Bahu, Manado \\ 95115, Indonesia \\ Email : eflinrainmamuko@gmail.com
}

\begin{abstract}
District of Siau Tagulandang Biaro had just started ti implement this rural and urban property taxes policy since January 2015. The number of unrecorded tax objects and taxpayer unclearness becomes a challenge for the district SITARO in increasing land tax and rural and urban buildingsd (PBB-P2). The purpose of this study is to know the strategy undertaken by the district of SITARO in overcoming the obstacles of the manny objects of taxes that have not been recorded and the unclearness of taxpayers and know level of effectiveness acceptance land tax and rural and urban buildingsd (PBB-P2). This type of research is descritive. The results of the research show the strategies undertaen by the SITARO district government is to re-register, update the data and deletion of data. The effectiveness level in 2015 is quite effective with the persenrage of $88 \%$ and in 2016 is effective with the percentage of $98 \%$.
\end{abstract}

Keywords: Land tax and Rural and Buildings, strategy, effectiveness

\section{PENDAHULUAN}

Salah satu penerimaan daerah adalah pajak. Pajak Bumi dan Bangunan Perdesaan dan Perkotaan merupakan salah satu jenis pajak yang termasuk dalam jenis Pajak Daerah Kabupaten/Kota yang sebelumnya di dalam Undang-Undang- Undang No.34 Tahun 2000 Pajak Bumi dan Bangunan belum ada di jenis pajak Kabupaten/Kota. Di Pemerintah kabupaten Kepulauan Siau Tagulandang Biaro sendiri mulai menerapkan Pajak Bumi dan Bangunan Pedesaan dan Perkotaan menjadi Pajak Daerah di mulai pada 1 Januari 2015. Mengingat masih terdapat kendala dalam meningkatkan penerimaan Pajak Bumi dan Bangunan Perdesaan dan Perkotaan (PBB-P2) di pemerintah kabupaten Kepulauan Siau Tagulandang Biaro antara lain masih banyaknya objek pajak yang belum terdata, ketidakjelasan wajib pajak, dan adanya tunggakan pajak yang di akibatkan karena ketidakjelasan wajib pajak sehingga wajib pajak tidak membayar kewajibanya sebagai wajib pajak. Ditetapkannya Pajak Bumi dan Bangunan menjadi pajak yang dikelolah oleh daerah yang berarti sepenuhnya penerimaan tersebut menjadi bagian langsung APBD. Berikut adalah target dan realisasi di Kabupaten Kepulauan SITARO pada tahun 2015 dan 2016. 
Tabel 1. Target serta Realisasi Penerimaan PBB-P2 Kabupaten SITARO tahun 2015-2016

\begin{tabular}{cccr}
\hline Tahun Anggaran & Target & Realisasi & Persentase (\%) \\
\hline 2015 & Rp. 701.652.432 & Rp. 617.181.227 & $88 \%$ \\
2016 & Rp. 709.950.987 & Rp. 694.836.157 & $98 \%$
\end{tabular}

Sumber: Badan Keuangan Kabupaten Kepulauan Siau Tagulandang Biaro

Tingkat realisasi belum mencapai target yang telah ditetapkan meskipun setiap tahunnya mengalami peningkatan. Maka dari itu, diperlukan strategi yang tepat untuk mengatasi kendala banyakknya objek pajak yang belum terdata dan ketidakjelasan wajib pajak agar target yang telah ditetapkan bisa tercapai dan manfaatnya dapat dirasakan secara maksimal oleh masyarakat Siau Tagulandang Biaro (SITARO). Penelitian ini bertujuan untuk mengetahui bagaimana strategi yang dilakukan oleh Badan Keuangan Kabuapaten Kepulauan Siau Tagulandang Biaro untuk mengatasi kendala banyaknya objek pajak yang belum terdata dan ketidakjelasan wajib pajak dalam rangka meningkatkan penerimaan PBB-P2 dan untuk mengetahui bagaimana tingkat efektivitas penerimaannya di Kabupaten Kepulauan Siau Tagulandang Biaro.

\section{TINJAUAN PUSTAKA}

Pengertian Akuntansi. Menurut Warren, et al (2014:3) system informasi yang menyediakan laporan bagi para pemangku kepentingan mengenai kondisi ekonomi serta aktivitas suatu perusahaan.

Pengertian Akuntansi Pajak. Pohan (2013: 10) akuntansi pajak adalah penyediaan informasi yang memiliki hubungan dengan perpajakan, serta bisnis dan transaksi keuangan dan aspek perpajakan dari suatu entitas.

Pengertian Pajak. Menurut Sari(2013:34) Pajak merupakan iuran dari masyarakat kepada negara yang sifatnya memaksa berdasarkan Undang-Undang atau aturan yang berlaku secara umum.

Pengertian Pajak Bumi dan Bangunan Perdesaan dan Perkotaan (PBB-P2). Pajak yang dikenakan atas kepemilikan atau dimanfaatkannya bumi atau bangunan kecuali digunakan untuk perkebunan, perhutanan,pertambangan. Munaroh (2014).

Pengertian Strategi. Berbagai cara untuk mencapai tujuan. Solihin (2012:64)

Jenis- Jenis Strategi. Menurut Mintberg dan Walters dalam Heene (2010: 60) :

1. Strategi yang Terencana.

2. Strategi Intrapreneur.

3. Strategi Ideologi.

4. Strategi Payung.

5. Strategi Proses.

6. Strategi Parsial.

7. Strategi Konsensus.

8. Strategi Pendukung

Perencanaan Strategis. Menurut Mahsun (2016:157) perencanaan strategis adalah proses yang menentukan tujuan serta strategi untuk mencapai tujuan dengan memperhatikan lingkungan eksternal dan internal.

Analisis SWOT. Menurut David (2012:8) mengatakan bahwa analisis SWOT adalah analisis yang terdiri atas kekuatan dan kelemahan dan digabungkan dengan peluang dan ancaman dari eksternal. 
Efektivitas. Membandingkan antara tingkat realisasi dengan target penerimaan yang telah dibuat. Bayangkara (2014:14).

Analisis Efektivitas. Rumus menghitung efektivitas penerimaan pajak adalah sebagai berikut:

$$
\text { Efektivitas }=\frac{\text { Realisasi }}{\text { Target }} \times 100 \%
$$

\section{METODE PENELITIAN}

Jenis Penelitian. Penelitian deskriptif yang bertujuan untuk menggambarkan, melukiskan secara sistematis mengenai fakta, sifat, hubungan serta peristiwa yang diselidiki Husnia (2016:4)

Tempat dan Waktu Penelitian. yaitu di Badan Keuangan Bidang Pendapatan Kabupaten Kepulauan Siau Tagulandang Biaro. Bulan Mei 2016 sampai dengan selesai.

Prosedur Penelitian. Melihat serta Menggali permasalahan yang ada di Badan Keuangan agar diteliti lebih lanjut, serta mengmpulkan data yang diperlukan dan menganalisis data kemudian mengambil kesimpulan atas hasil penelitian.

Jenis data. Data Kualitatif menurut Sutarman (2012:3) berupa data yang berbentuk katakata yang dihasilkan dari teknik pengumpulan data berupa wawancara, analisis dokumen, dan diskusi terfokus atau observasi. Dalam penelitan ini penulis menggunakan data kualitatif yang dihasilkan dari wawancara dan bahan tertulis.

Metode Analisis Data. Menggunakan metode SWOT analysis. Metode ini digunakan untuk mendeskripsi bagaimana strategi pemerintah Kabupaten Kepuauan Siau Tagulandang Biaro dalam mengatasi kendala yang berkaitan dengan penerimaan PBB-P2.

\section{HASIL PENELITIAN DAN PEMBAHASAN}

\subsection{Hasil Penelitian}

Berdasarkan informasi yang diperoleh dari wawancara dengan pihak Badan keuangan

Kab Kep SITARO bidang pendapatan maka strategi yang dilakukan oleh Badan Keuangan Kab Kep SITARO adalah sebagai berikut:

1. Perekaman Data Ulang. Strategi pertama yang dilakukan oleh pemerintah Kabupaten Kepulauan Siau Tagulandang Biaro untuk mengatasi kendala banyaknya objek pajak yang belum terdata dan ketidakjelasan wajib pajak dalam rangka meningkatkan penerimaan Pajak Bumi Bangunan Perdesaan dan Perkotaan di kabupaten Siau Tagulandang Biaro yaitu dengan perekaman data ulang. Perekaman data ulang ini dilakukan dengan cara bekerja sama dengan pemerintah yang ada di setiap kecamatan dan pemerintah yang ada di setiap desa untuk bersama turun langsung melihat keadaan objek pajak yang masi baru dan tentunya belum terdaftar. Bukan hanya memperhatikan objek pajak baru namun pemerintah juga melihat perubahan keadaan pada objek pajak yang misalnya dulunya wajib pajak hanya memiliki rumah yang berukuran kecil namun sudah direnovasi dengan ukuran yang lebih besar, dan pemerintah juga mencari tahu tentang kejelasan wajib pajak yang objek pajaknya sudah tidak di bayar lagi. Misalnya wajib pajak telah menjual objek pajaknya kepada orang lain tanpa membuat surat keterangan di pihak dinas pendapatan maka di saat jatuh tempo pembayaran pajak wajib pajak tersebut tidak mau membayar objek pajak tersebut karena objek pajak tersebut sudah bukan menjadi miliknya lagi. Hal ini yang mengakibatkan ketidakjelasan wajib pajak dan menimbulkan piutang pajak.

2. Pemutakhiran Data. Strategi kedua yang dilakukan oleh Pemeritah Kabupaten Siau Tagulandang Biaro adalah dengan melakukan Pemutakhiran data. Pemutakhiran data 
dilakukan dengan cara mencocokkan data jumlah wajib pajak serta nomor wajib pajak kemudian dimasukan zona daerah SISMIOP. Hal ini dibantu oleh pemerintah desa.

3. Strategi yang ketiga yang di lakukan oleh pemerintah kabupaten Siau Tagulandang Biaro adalah Penghapusan Data. Setelah melakukan perekaman data ulang, pemutakhiran data maka langka terakhir adalah penghapusan data. Penghapusan data ini di lakukan atas dasar ketidakjelasan wajib pajak dan objek pajak yang mungkin mengalami kesalahan saat pendataan objek pajak.

Tingkat Efektivitas Penerimaan PBB P2 Kabupaten Kepulauan Siau Tagulandang Biaro. Berdasarkan data yang diperoleh dari Badan Keuangan Kabupaten Kepulauan Siau Tagulandang Biaro tingkat presentase efektivitas penerimaan Pajak Bumi dan Bangunan Perdesaan dan Perkotaan adalah:

Tabel 1. Tingkat Efektivitas Penerimaan PBB-P2 Kabupaten Kepulauan Siau Tagulandang Biaro

\begin{tabular}{lccrl}
\hline Tahun Anggaran & Target & Realisasi & Persentase & Tingkat efektivitas \\
\hline 2015 & Rp.701.652.432 & Rp. 617.181.227 & $88 \%$ & Cukup efektif \\
2016 & Rp. 709.950 .987 & Rp. 694.836.157 & $98 \%$ & Efektif \\
\hline
\end{tabular}

Sumber: Badan Keuangan Kabupaten Siau Tagulandang Biaro

Berdasarkan Tabel 1 terlihat bahwa tingkat efektivitas PBB-P2 pada tahun 2015 adalah cukup efektif dengan target sebesar Rp 701.652.432 dengan mencapai realisasi hanya sebesar $88 \%$, sedangkan pada tahun 2016 tingkat efektivitas menjadi efektif dengan target sebesar 709.950.987 dengan realisasi sebesar Rp. 694.836.157.

\subsection{Pembahasan}

Analisis SWOT (Strenght-Weaknesses-Opportunity-Threats) Strategi Mengatasi Kendala Banyaknya Objek Pajak yang Belum Terdata dan Ketidakjelasan Wajib Pajak PBBP2 di Kabupaten Kepulauan Siau Tagulandang Biaro. 
Tabel 2. Matrix SWOT Mengatasi Kendala Banyaknya Objek Pajak dan Ketidakjelasan Wajib Pajak dalam Rangka Meningkatkan Penerimaan PBB-P2

\begin{tabular}{|c|c|c|}
\hline EFAS & $\begin{array}{l}\text { Kekuatan/Strenght }(\boldsymbol{S}) \\
\text { 1. UU Nomor } 32 \text { Tahun } 2004 \text { dan } \\
\text { UU Nomor } 28 \text { Tahun } 2009 \text { yang } \\
\text { bersifat memaksa }(0,20) \\
\text { 2. Pertumbuhan ekonomi di Kab } \\
\text { Siau Tagulandang Biaro yang } \\
\text { Dinamis. }(0,15) \\
\text { 3. Pengelolaan sistem informasi } \\
\text { PBB-P2 di Kabupaten } \\
\text { Kepulauan Siau Tagulandang } \\
\text { Biaro yang sudah menggunakan } \\
\text { SISMIOP }(0,15)\end{array}$ & $\begin{array}{l}\text { Kelemahan/Weakness }(\mathbf{W}) \\
\text { 1. } \\
\text { Pelayanan yang ada belum } \\
\text { maksimal }(0,10) \\
\text { 2. } \\
\text { Fasilitas yang mendukung untuk } \\
\text { mengujungi langsung objek } \\
\text { pajak belum memadai }(0,15) \\
\text { 3. SDM yang masi kurang di } \\
\text { Badan Keuangan yang dapat } \\
\text { membantu dalam penyuluhan } \\
\text { peraturan PBB-P2, dan } \\
\text { pengoperasian SISMIOP }(0,10)\end{array}$ \\
\hline $\begin{array}{ll} & \text { Peluang/ Oppurtunity } \\
\text { 1. } & \text { Diatur oleh Peraturan } \\
\text { Daerah }(0,20) \\
\text { 2. }\end{array}$ & 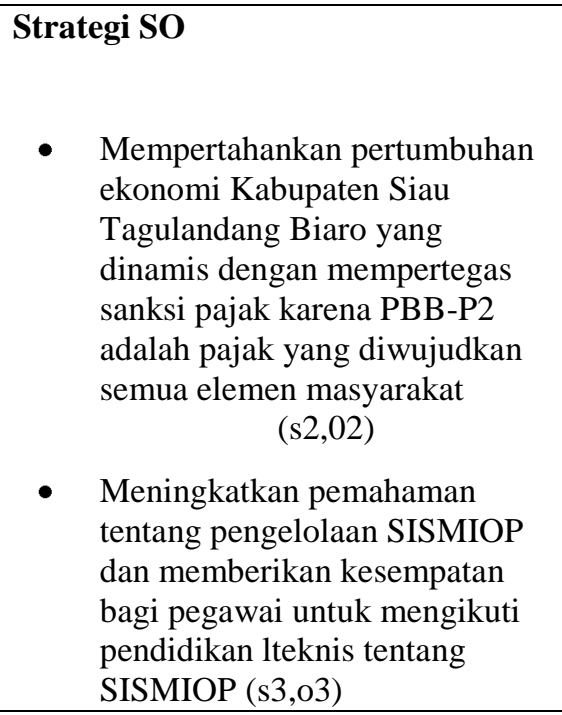 & $\begin{array}{l}\text { - SDM yang harus ditambah } \\
\text { agar dapat membantu dalam } \\
\text { penyuluhan peraturan PBB-P2 } \\
\text { dan pengoperasian SISMIOP } \\
\text { sehingga peraturan daerah } \\
\text { dapat di tegakkan secara tegas } \\
\text { (w3,o1) } \\
\text { Menambah fasilitas agar } \\
\text { kepercayaan masyarakat } \\
\text { terhadap pemerintah menjadi } \\
\text { meningkat sehingga } \\
\text { penerimaan PBB-P2 menjadi } \\
\text { meningkat.(w2,o2) }\end{array}$ \\
\hline $\begin{array}{l}\text { Ancaman /Threats }(\boldsymbol{T}) \\
\text { 1. } \\
\text { Perkembangan } \\
\text { globalisasi yang } \\
\text { menuntut keterbukaan } \\
(0,15) \\
\text { 2. } \\
\text { Masih terdapat beberapa } \\
\text { Masyarakat Kabupaten } \\
\text { Kepulauan Siau } \\
\text { Tagulandanng Biaro } \\
\text { yang masih belum } \\
\text { menyadari pentingnya } \\
\text { membayar pajak }(0,20) . \\
\text { Pencapaian Realisasi } \\
\text { dari pemerintah yang } \\
\text { belum mencapai target } \\
\text { yang mengakibatkan } \\
\text { persepsi buruk di } \\
\text { masyarakat }(0,20)\end{array}$ & 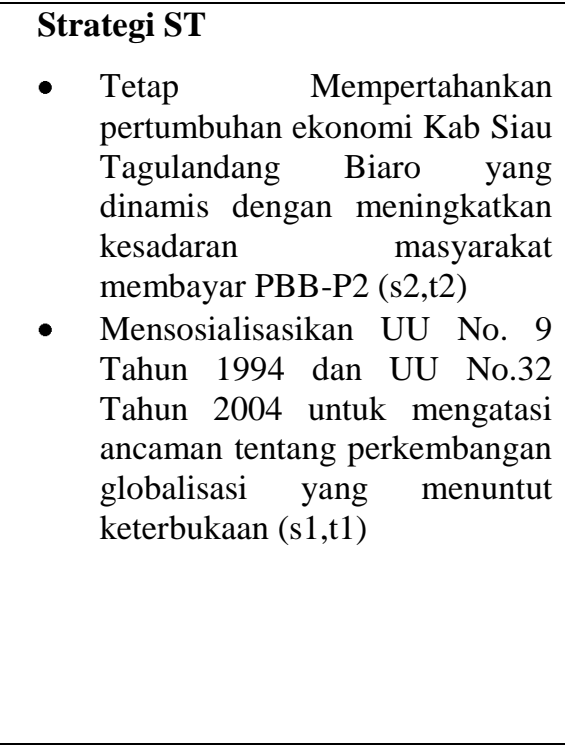 & \begin{tabular}{l}
\multicolumn{1}{c}{ Strategi WT } \\
- $\quad$ Memaksimalan pelayanan \\
dengan memperhatikan \\
perkembangan globalisasi \\
(w1,t1) \\
Menambah SDM sehingga \\
dapat membantu dalam \\
penyuluhan dan pengelolaan \\
program SISMIOP sehingga \\
realisasi pemerintah Daerah \\
mencapai target sehingga tidak \\
menimbulkan persepsi buruk di \\
mata masyarakat $(\mathrm{w} 3, \mathrm{t} 3)$
\end{tabular} \\
\hline
\end{tabular}

Sumber: Data diolah 2018 
Penentuan strategi baru berdasarkan matriks SWOT mengatasi kendala banyaknya objek Pajak yang belum terdata dan ketidakjelasan wajib pajak dalam rangka meningkatkan penerimaan PBB-P2.

1. Penambahan Tenaga Lapangan

Banyaknya objek pajak yang baru di Kabupaten Siau Tagulandang Biaro membuat pendataan menjadi tidak merata oleh karena itu penambahan tenaga lapangan harus wajib dilakukan karena tugas dari pekerja lapangan sangat penting dalam hal pendataan dan penilaian terhadap objek PBB-P2.

2. Pemerintah harus memfasilitasi SDM dalam menempuh pendidikan tentang PBB-P2 karena minimnya SDM yang menguasai tentang PBB-P2 di Dinas Keuangan Kabupaten Kepulauan Siau Tagulandang Biaro.

3. Memperbaiki sistem pengelolaan PBB-P2.

4. Pemerintah harus mampu membuat serta mengambil langkah yang tegas dalam pemberian sanksi kepada masyarakat yang tidak membayar serta melaporkan pajak yang dimilikinya.

Tingkat Efektivitas Penerimaan PBB-P2 di Kabupaten Kepulauan Siau Tagulandang Biaro. Berdasarkan tabel 1 di tahun 2015 tidak mencapai target yang ditetapkan yaitu hanya $88 \%$ ini terjadi karena pelimpahan dari pusat kedaerah sehingga validasi keakuratan data belum dilakukan pemerintah daerah secara maksimal. Sehingga pada saat pelimpahan ke daerah data tersebut ditolak wajib pajak karena tidak sesuai dengan kepemilikkan, yang mereka miliki sehingga masyarakat tidak melunasi PBB-P2 tersebut. Tahun 2016 naik cukup signifikan yaitu 98\% dikategorikan efektif, hal ini terjadi karena adanya penambahan wajib baru dan objek pajak baru.

\section{KESIMPULAN DAN SARAN}

\subsection{Kesimpulan}

1. Sesuai hasil penelitian strategi yang di lakukan oleh Badan Keuangan Kabupaten Kepulauan Siau Tagulandang Biaro dalam mengatasi kendala banyaknya objek pajak yang belum terdata dan ketidakjelasan wajib pajak dalam rangka meningkatkan penerimaan PBB-P2 di Kabupaten Kepulauan Siau Tagulandang Biaro adalah melakukan Perekaman Data Ulang, melakukan Pemutakhiran Data, dan Penghapusan Data yang tidak sesuai dengan kepemilikan atau mengalami kesalahan saat pendataan objek pajak.

2. Efektivitas penerimaan PBB-P2 Kabupaten Kepulauan Siau Tagulandang Biaro pada Tahun 2015 adalah Cukup Efektif dan pada Tahun 2016 mengalami peningkatan menjadi efektif.

\subsection{Saran}

1. Peneliti selanjutnya diharapkan dapat menganalisis perbandingan jumlah penerimaan PBB-P2 sebelum dan sesudah di lakukan strategi mengatasi kendala banyaknya objek pajak yang belum terdata dan ketidakjelasan wajib pajak agar terlihat jelas perkembangan peningkatan PBB-P2.

2. Bagi Instansi, harus adanya tindakan tegas kepada masyarakat yang tidak mau melaporkan, membayar pajak yang dimilikinya.

3. Rutin melakukan sosialisasi tentang PBB-P2 agar mendorong kesadaran Wajib Pajak untuk menaati peraturan degan rutin membayar dan melaporkan objek pajak yang dimiliki oleh wajib pajak. 


\section{DAFTAR PUSTAKA}

Bayangkara, IDK. 2014. Audit Manajemen Prosedur dan Implementasi Cetakan Ketujuh, Jakarta: Salemba Empat

David, Fred R. 2012. Strategic Management (Manajemen Strategi Konsep). Penerbit : Salemba Empat. Jakarta.

Heene Aime, Desmidt Sebastian, Afiif Haisal, Abdullah Ismeth. 2010. Manajemen Strategik Keorganisasian Publik. Bandung : PT Refika Aditama.

Husnia. Fitria Nur. 2016. Analisis Penerapan Elektronik Pajak Bumi dan Bangunan (E-PBB) (study pada Dinas Pendapatan Daerah Kabupaten Lamongan). Jurnal Perpajakan (JEJAK). Vol 9 No. 12016

Mahsun Mohamad, Firma Sulistyowaty, dan Hibertus A P. 2016.Akuntansi Sektor Publik. Edisi Ketiga. Yogyakarta:BPFE.

Munaroh, Siti. 2014.'Dampak Pengalihan PBB-P2 menjadi Pajak Daerah Peluang dan Tantangan"Jurnal Riset Manejemen dan Akuntansi Vol 1,No1 February 2014.

Pohan, Chairil Anwar. 2013. Manajemen Perpajakan. PT Gramedia Pustaka Utama. Jakarta.

Republik Indonesia, Undang-undang Nomor 28 Tahun 2009 Tentang Pajak Daerah dan Retribusi Daerah.

Sari, Diana. Konsep Dasar Perpajakan. Bandung:Refika Aditama.

Solihin. Ismail. 2012. Manajemen Strategik. Jakarta: Penerbit Erlangga

Sutarman. 2012. Pengantar Teknologi Informasi. Bumi Aksara. Jakarta.

Warren, Carl S, Reeve, James M, dan Duchach Jonathan E. 2014. Pengantar AkuntansiAdaptasi Indonesia. Edisi 25. Salemba Empat. Jakarta. 